\title{
A study to assess proportion of the maternal near miss to maternal death in a tertiary care teaching hospital of North East India
}

\author{
Pradip Sarkar, Jahar Lal Baidya*, Asish Kumar Rakshit
}

Department of Obstetrics and Gynecology, Agartala Government Medical College, Agartala, Tripura, India

Received: 16 March 2020

Accepted: 22 April 2020

\section{*Correspondence:}

Dr. Jahar Lal Baidya,

E-mail: iamjlbaidya@hotmail.com

Copyright: () the author(s), publisher and licensee Medip Academy. This is an open-access article distributed under the terms of the Creative Commons Attribution Non-Commercial License, which permits unrestricted non-commercial use, distribution, and reproduction in any medium, provided the original work is properly cited.

\begin{abstract}
Background: The objective of present study was to assess the proportion of maternal near miss and maternal death and the causes involved among patients attending obstetrics and gynaecology department of Agartala Govt. Medical College of North Eastern India.

Methods: Potentially life-threatening conditions were diagnosed, and those cases which met WHO 2009 criteria for near miss were selected. Maternal mortality during the same period was also analyzed. Patient characteristics including age, parity, gestational age at admission, booked, mode of delivery, ICU admission, duration of ICU stay, total hospital stay and surgical intervention to save the life of mother were considered. Patients were categorized by final diagnosis with respect to hemorrhage, hypertension, sepsis, dystocia (direct causes) anemia, thrombocytopenia, and other medical disorders were considered as indirect causes contributing to maternal near miss and deaths.

Results: The total number of live births during the study period (January 2017 to June, 2018) was 9378 and total maternal deaths were 37 with a maternal mortality ratio of 394.5/1 lakh live births. Total near miss cases were 96 with a maternal near miss ratio of 10.24/1000 live births. Maternal near miss to mortality ratio was 2.6. Of the 96 maternal near miss cases - importantly $20.8 \%$ were due to haemorrhage, $19.8 \%$ were due to hypertension, $13.5 \%$ were due to sepsis, and $11.5 \%$ were due to ruptured uterus. In maternal death group (n-37), most important causes were hypertensive $(40.5 \%)$ followed by septicemia (21.6\%), haemorrhage (10.8).

Conclusions: Haemorrhage, hypertensive disorders and sepsis were the leading causes of near miss events as well as maternal deaths.
\end{abstract}

Keywords: Audit of maternal near miss, Maternal death, Maternal near miss, Obstetric intensive care unit, Severe

\section{INTRODUCTION}

A maternal near miss $(\mathrm{MNM})$ is an event in which a pregnant woman comes close to maternal death, but does not die - a "near-miss". Traditionally, the analysis of maternal deaths has been the criteria of choice for evaluating women health and the quality of obstetric care.

Due to the success of modern medicine such deaths have become very rare in developed countries, which have led to an increased interest in analysing so-called "near miss" events. Maternal near-miss has been defined by WHO as 'a woman who almost died but survived complications during pregnancy, childbirth' or within 42 days of delivery'. ${ }^{1}$

Maternal near miss cases have similar pathways as maternal deaths, with the advantages of offering a larger number of cases for analysis, greater acceptability of individuals. Since death did not occur, possibility of interviewing the woman herself is there. Pregnant women health status is not reflected by mortality indicators alone. Hence for the last two decades, the concept of conducting a maternal near miss (MNM) review has gained importance as additional strategy to help identify gaps in health service provision. 
Previously there was no standard set of criteria for identifying maternal near miss cases, so wider application of this concept was limited. But in 2009, WHO has come up with clinical, laboratory, management-based criteria for identification of these cases. ${ }^{1}$

Maternal near miss audit has been considered a less threatening approach than maternal death audit, and can be used to identify what needs to be done to improve the quality of maternal health care. Compared with maternal death review, the fear of blame and punishment is less in near miss review so, if a near miss review is performed effectively, it can in practice more easily lead to implementation of changes that will improve the quality of services. ${ }^{2}$

Near miss cases generally occur more frequently than maternal deaths and therefore a more reliable quantitative analysis can be carried out, which can provide a more comprehensive profile of health system functioning. ${ }^{3,4}$

Identification of the obstacles and gaps in the health system and a coordinated approach to resolve these can ultimately lead to an improved health system. Multiple studies performed around the World as well as many parts of India especially for the last two decades on maternal near miss. But there is paucity of information regarding maternal near miss in this part of the country; hence the present study has been conducted to study the maternal near miss events in Agartala Govt. Medical College which is one of the premier institutes of North Eastern Zone of India.

\section{METHODS}

It is an observational, cross sectional study conducted in department of obstetrics and gynecology at Agartala Government Medical College Hospital for 2 years (January 2017 to December 2018), among which 1.5 years for sample collection and 6 months for analysis of the sample). All patients of maternal near miss and maternal deaths within one and half year period in hospital have been included in my study.

\section{Inclusion criteria}

- All pregnant women of reproductive age group who had felt in the WHO maternal near miss criteria

- All pregnant women who died due to direct or indirect cause of pregnancy, childbirth, or within 42 days of delivery.

\section{Exclusion criteria}

- All pregnant women of reproductive age group who had felt in the WHO maternal near miss criteria

- All pregnant women who died due to direct or indirect cause of pregnancy, childbirth, or within 42 days of delivery.
An audit of maternal near miss cases from January 2017 to June 2018 was taken. Agartala Govt. Medical College hospital is a tertiary referral hospital for both public and private hospitals of Tripura. In addition to providing twenty-four-hour emergency obstetric services, the hospital also provides antenatal care and delivery services for both low and high-risk pregnant women. Hospital has 24-hour facility for blood component therapy, high dependency unit (HDU) in labor room complex.

Potentially life-threatening conditions were diagnosed, and those cases which met WHO 2009 criteria for near miss were selected. WHO criteria include a set of clinical laboratories and management-based criteria.

Maternal mortality during the same period was also analysed. Patient characteristics including age, parity, gestational age at admission, booked 5 ( $>3$ antenatal visits to study hospital irrespective of gestational age), mode of delivery ICU admission, duration of ICU stay, total Hospital stay duration and surgical intervention to save the life of mother were considered.

Patients were categorized by final diagnosis with respect to hemorrhage, hypertension, sepsis, dystocia (direct causes) anemia, thrombocytopenia, and other medical disorders were considered as indirect causes contributing to maternal near miss and deaths. Patient had undergone necessary investigations as per requirement.

\section{Statistical analysis}

Data collected were presented in frequency and percentage and data analysis has been done in Epiinfo version 7.0. Statistical analysis was done using Person Chi Square test. A $p$ value of $<0.05$ were deemed as statistically significant.

\section{RESULTS}

The total number of live births during the study period (January 2017 to June, 2018) was 9378 and total maternal deaths were 37 with a maternal mortality ratio of 394.5/1 lakh live births.

Total near miss cases were 96 with a maternal near miss ratio of $10.24 / 1000$ live births. maternal near miss to mortality ratio was 2.6 .

Table 1 shows that, the majorities of women were 20-29 years in maternal near miss group $(55.2 \%)$ and maternal death group (48.6\%).

The majority of patients $(73 \%)$ were multipara in maternal near miss group and the majority of patients $(62.2 \%)$ were Primi para in maternal death group. $42.7 \%$ were term gestation and $22.9 \%$ were post-delivery/ post abortion stage in maternal near miss group and in contrast $43.2 \%$ were term gestation and $27 \%$ were postdelivery/post-abortion stage in maternal death group. 
Table 1: Baseline parameters of the patients at the onset of treatment.

\begin{tabular}{|lllll|}
\hline Parameters & & Maternal near miss (\%) & Maternal death (\%) & Total (\%) \\
\cline { 2 - 5 } Age & $<20$ & $10.4 \%$ & $24.3 \%$ & $14.3 \%$ \\
\cline { 2 - 5 } & $20-29$ & $55.2 \%$ & $48.6 \%$ & $53.4 \%$ \\
\cline { 2 - 5 } & $>29$ & $34.4 \%$ & $27.1 \%$ & $32.3 \%$ \\
\hline \multirow{2}{*}{ Parity } & Primi & $27.1 \%$ & $62.2 \%$ & $36.4 \%$ \\
\cline { 2 - 5 } & Multi & $72.9 \%$ & $37.8 \%$ & $63.6 \%$ \\
\hline \multirow{2}{*}{ POG } & Antenatal & $35.4 \%$ & $35.1 \%$ & $35.3 \%$ \\
\cline { 2 - 5 } & Intranatal & $19.8 \%$ & $0.0 \%$ & $50.4 \%$ \\
\cline { 2 - 5 } & Postnatal & $44.8 \%$ & $64.9 \%$ & $76 \%$ \\
\hline \multirow{2}{*}{ Literacy } & Literate & $75 \%$ & $78.4 \%$ & $24 \%$ \\
\cline { 2 - 5 } Booking status & Illiterate & $25 \%$ & $21.6 \%$ & $36.1 \%$ \\
\cline { 2 - 5 } & Booked & $37.5 \%$ & $32.4 \%$ & $88 \%$ \\
\hline \multirow{2}{*}{ Referral status } & Unbooked & $62.5 \%$ & $67.6 \%$ & $12 \%$ \\
\cline { 2 - 5 } & Referred & $88.5 \%$ & $13.5 \%$ & \\
\hline
\end{tabular}

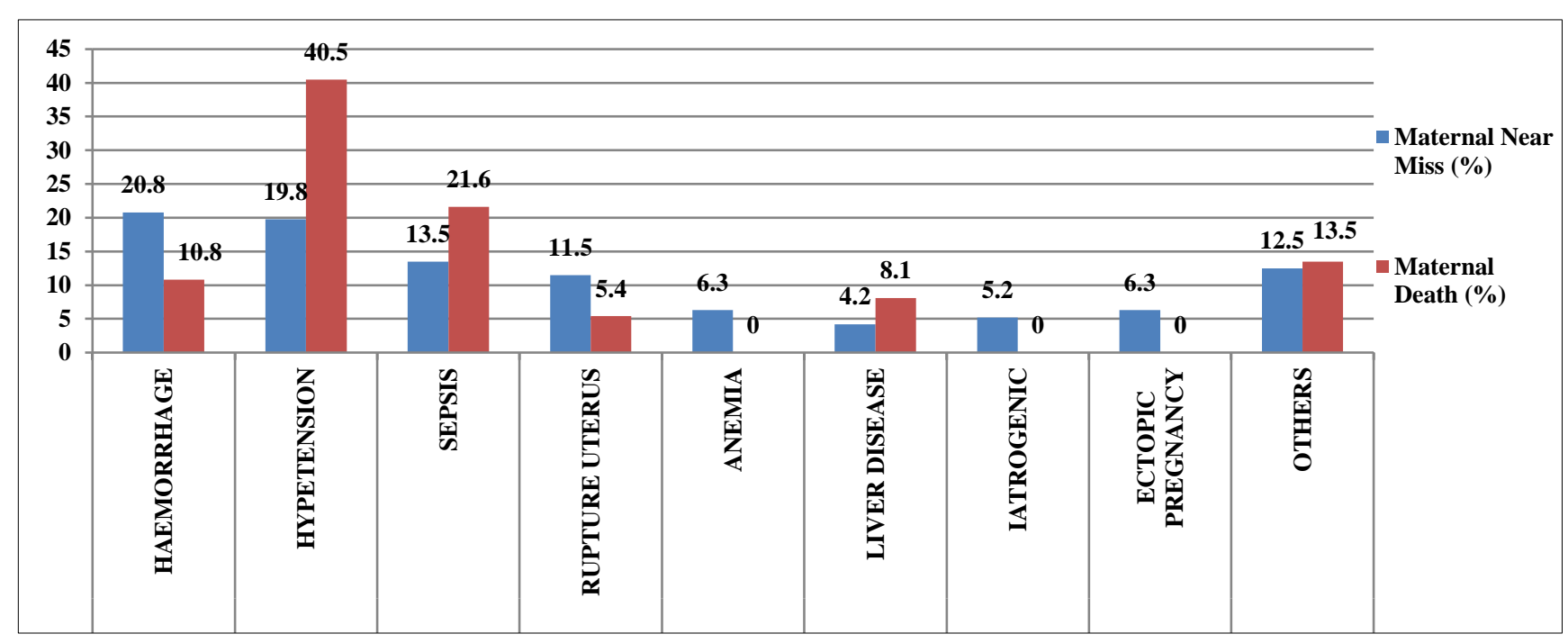

Figure 1: Graphical representation of underlying causes distribution in maternal near miss and maternal death group.

The most patients $(38 \%)$ are educated up to $6^{\text {th }}-12^{\text {th }}$ class followed by literate up to $5^{\text {th }}$ class $(30 \%)$, illiterate $(24 \%)$, beyond $12(8 \%)$ among all study subjects. the maximum patients are un booked to any centre whether it was maternal near miss $(62.5 \%)$ or maternal death $(67.6 \%)$. The majority $(87.5 \%)$ lived in a rural zone; $88.5 \%$ were referred and $22.9 \%$ are referred from more than one centre in maternal near miss group in contrast the majority $(91.9 \%)$ lived in a rural zone; $86.5 \%$ were referred and $8.1 \%$ are referred from more than one centre in maternal death group. It shows $19 \%$ of patients admitted in ICU (medical ICU) overall. Figure 1 shows, of the 96 maternal near miss cases, $20.8 \%$ were due to haemorrhage, $19.8 \%$ were due to hypertension, $13.5 \%$ were due to sepsis, $11.5 \%$ were due to ruptured uterus, $6.3 \%$ were due to anemia, $5.2 \%$ were due to iatrogenic causes, $6.3 \%$ were due to ectopic pregnancy and $12 \%$ were due to other causes. Of the other causes 3 had adherent placenta, 2 had Guillain-Barre syndrome, 2 had acute pancreatitis, 1 had bleeding disorder with raised coagulation time around 9 minutes, 1 had cerebral malaria, 1 had chronic kidney disease, 1 had cardiomyopathy and 1 had intrauterine arterio-venous malformation with uncontrolled secondary postpartum hemorrhage following LSCS for which peri partum hysterectomy was done to save the life. In maternal death group $(n=37)$, most of the patients were hypertensive $(40.5 \%)$ followed by septicaemia $(21.6 \%)$, haemorrhage (10.8), liver disorder $(8.1 \%)$, rupture uterus $(5.4 \%)$ and others accounts for $13.5 \%$. Of the other causes 1 were had Guillain-Barre syndrome, 1 had cerebral malaria, 1 had Acute Kidney Injury, 1 had cardiomyopathy, 1 had gastroduodenal artery aneurysm rupture incidentally diagnosed during re-laparotomy for hemoperitoneum. 
Table 2: Organ dysfunction distribution in maternal near miss and maternal death group.

\begin{tabular}{|c|c|c|c|c|c|c|}
\hline Organ dysfunction & $\begin{array}{l}\text { Maternal } \\
\text { near miss (n) }\end{array}$ & $\begin{array}{l}\text { Maternal near } \\
\text { miss }(\%)\end{array}$ & $\begin{array}{l}\text { Maternal } \\
\text { death }(\mathbf{n})\end{array}$ & $\begin{array}{l}\text { Maternal } \\
\text { death }(\%)\end{array}$ & Total (n) & Total $(\%)$ \\
\hline Hematologic & 35 & $36.5 \%$ & 4 & $10.8 \%$ & 39 & $29.3 \%$ \\
\hline Respiratory & 8 & $8.3 \%$ & 9 & $24.3 \%$ & 17 & $12.8 \%$ \\
\hline Cardiac & 4 & $4.2 \%$ & 0 & $0.0 \%$ & 4 & $3.0 \%$ \\
\hline Liver & 4 & $4.2 \%$ & 3 & $8.1 \%$ & 7 & $5.3 \%$ \\
\hline Kidney/urinary & 2 & $2.1 \%$ & 1 & $2.7 \%$ & 3 & $2.2 \%$ \\
\hline CNS & 9 & $9.4 \%$ & 8 & $21.6 \%$ & 17 & $12.8 \%$ \\
\hline GI & 1 & $1.0 \%$ & 0 & $0.0 \%$ & 1 & $0.8 \%$ \\
\hline Genital & 18 & $18.8 \%$ & 3 & $8.1 \%$ & 21 & $15.8 \%$ \\
\hline Sepsis / multiorgan dysfunction & 13 & $13.5 \%$ & 8 & $21.6 \%$ & 21 & $15.8 \%$ \\
\hline Musculoskeletal & 2 & $2.1 \%$ & 1 & $2.7 \%$ & 3 & $2.2 \%$ \\
\hline Total & 96 & $100.0 \%$ & 37 & $100.0 \%$ & 133 & $100.0 \%$ \\
\hline
\end{tabular}

Table 3: Delivery mode distribution in both groups.

\begin{tabular}{|lllllll|}
\hline Delivery mode & $\begin{array}{l}\text { Maternal } \\
\text { near miss }(\mathbf{N})\end{array}$ & $\begin{array}{l}\text { Maternal near } \\
\text { miss }(\%)\end{array}$ & $\begin{array}{l}\text { Maternal } \\
\text { death }(\mathbf{N})\end{array}$ & $\begin{array}{l}\text { Maternal } \\
\text { death (\%) }\end{array}$ & Total (N) & Total $(\%)$ \\
\hline Normal vaginal & 33 & $34.4 \%$ & 16 & $43.2 \%$ & 49 & $36.8 \%$ \\
\hline Caesarean section & 28 & $29.2 \%$ & 3 & $8.1 \%$ & 31 & $23.3 \%$ \\
\hline Ventouse & 1 & $1.0 \%$ & 0 & $0 \%$ & 1 & $0.8 \%$ \\
\hline Laparotomy & 20 & $20.8 \%$ & 3 & $8.1 \%$ & 23 & $17.3 \%$ \\
\hline Undelivered & 14 & $14.6 \%$ & 15 & $40.6 \%$ & 29 & $21.8 \%$ \\
\hline Total & 96 & $100.0 \%$ & 37 & $100.0 \%$ & 133 & $100.0 \%$ \\
\hline
\end{tabular}

Table 4: Associated responsible/identified factors distribution for maternal near miss and maternal death.

\begin{tabular}{|lllllll|}
\hline Delivery mode & $\begin{array}{l}\text { Maternal } \\
\text { near miss }(\mathbf{N})\end{array}$ & $\begin{array}{l}\text { Maternal near } \\
\text { miss }(\%)\end{array}$ & $\begin{array}{l}\text { Maternal } \\
\text { death }(\mathbf{N})\end{array}$ & $\begin{array}{l}\text { Maternal } \\
\text { death }(\%)\end{array}$ & Total $(\mathbf{N})$ & Total $(\%)$ \\
\hline Personal & 54 & $56.3 \%$ & 19 & $51.4 \%$ & 73 & $54.9 \%$ \\
\hline Logistics & 23 & $24.0 \%$ & 7 & $18.9 \%$ & 30 & $22.6 \%$ \\
\hline Referral facility lack & 1 & $1.0 \%$ & 9 & $24.3 \%$ & 10 & $7.5 \%$ \\
\hline Present facility lack & 18 & $18.8 \%$ & 2 & $5.4 \%$ & 20 & $15.4 \%$ \\
\hline Total & 96 & $100.0 \%$ & 37 & $100.0 \%$ & 133 & $100.0 \%$ \\
\hline
\end{tabular}

Table 2 shows, that major organ involved in maternal near miss were hematologic $(36.5 \%)$, genital $(18.8 \%)$, sepsis leading to multiorgan dysfunction (13.5\%) followed by CNS $(9.4 \%)$ respiratory $(8.3 \%)$, cardiac $(4.2 \%)$, liver $(4.2 \%)$, then others. In contrast major organ involved in maternal death were respiratory $(24.3 \%)$, CNS (21.6\%), sepsis leading to multiorgan dysfunction $(21.6 \%)$, hematologic $(10.8 \%)$, then liver $(8.1 \%)$, genital $(8.1 \%)$ and others.

Table 3 shows, of the all women in maternal near miss $34.4 \%$ had vaginal delivery, 29.2 delivered by caesarean section. In maternal death group $40.6 \%$ patient died undelivered, $43.2 \%$ are delivered vaginally, $8.1 \%$ patient required caesarean section.

Table 4 shows, maximum patients had personal problems $(56.3 \%)$ leading to delayed arrival to hospital, $24 \%$ patients had logistic problems, $18.8 \%$ had facility lack in maternal near miss group whereas $51.4 \%$ had personal problems leading to delayed arrival to hospital, $18.9 \%$ had logistic problems, $24.3 \%$ had facility related problems, $5.4 \%$ had health personnel related issues in maternal death group.

\section{DISCUSSION}

Total numbers of near miss were 96 and maternal deaths were 37 in 18 months study period. Total live birth during that period in study hospital was 9378. The MNM ratio was $10.24 / 1000$ live births in study center. Previous reports of near-miss rates from India ranged from 3.98 to $17.38 / 1000$ live births. ${ }^{6}$

The majority of patients $(73 \%)$ were multipara in maternal near miss group and the majority of patients $(62.2 \%)$ were primipara in maternal death group. In contrast Roopa PS et al also showed primipara were 
slightly more $(56.4 \%)$ in the near miss group and multiparas are slightly more $(52.2 \%)$ in maternal death group. ${ }^{7}$ In contrast Reena RP et al in their study showed $37.5 \%$ were Primigravida women in maternal near miss group. ${ }^{8} 62.5 \%$ patients were un booked to any centre in maternal near miss group and in Maternal Death group $67.6 \%$ patients were un booked to any centre. RP Reena et al in their study showed $15.6 \%$ patients are un booked to any centre. ${ }^{8}$

In maternal near miss group $16.7 \%$ admitted in ICU and in maternal death group it is $27 \%$. In contrast RP Reena et al in their study showed a total of $62.6 \%$ of the cases required ICU admission. ${ }^{8}$ Non availability of separate obstetric ICU may be one of the important reasons for less ICU admission. Financial constraint was second important cause. It is also important to note here non availability of dedicated exclusive obstetric ICU at right time may be responsible for higher maternal mortality ratio in study centre.

Of the 96 maternal near miss cases $20.8 \%$ had haemorrhage, $19.8 \%$ had hypertension $13.5 \%$ had sepsis and $11.5 \%$ had ruptured uterus. Of 37 maternal deaths maximum $(40.5 \%)$ had hypertensive disorder followed by septicemia $(21.6 \%)$, haemorrhage $(10.8 \%)$. In contrast PS Roopa et al also showed among the causes of near miss events, hemorrhage was the leading cause with $44.2 \%$, and hypertension was $23.6 \% .^{7}$ Reena RP et al in their study showed $40.6 \%$ had severe pre-eclampsia, $21.8 \%$ had abruptio placenta, and $12.5 \%$ had severe sepsis as the underlying obstetric problem. ${ }^{8}$ This finding is compatible with most studies from high and middle-income

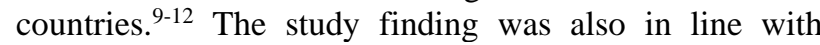
studies conducted in other African countries. ${ }^{13-15}$

A previous study in Ethiopia also reported hypertensive disorder as the primary cause, and obstetric hemorrhage as the second leading cause of maternal near-miss. ${ }^{16}$ High percentages of hypertensive disorder and obstetric hemorrhage might be indicative of some form of delay in managing obstetric complications by the facility staff. The rate was as compared to some of the other African countries that had been studied. ${ }^{14-17}$ Jyoti RC et al showed main causes of maternal near misses were hypertensive disorders of pregnancy $(46 \%)$ followed by haemorrhage $37 \%$, sepsis $7 \%$ and others $10 \%$ and the main cause of maternal mortality was hypertensive disorders of pregnancy $(25 \%)$ followed by haemorrhage and sepsis $17 \%$ each. Amniotic fluid embolism comprised 12\% followed by anemia and heart disease $8 \%$ each. Other causes comprised $10 \% .^{18}$

The major organ involved in maternal near miss were hematologic $(36.5 \%)$, genital $(18.8 \%)$, sepsis leading to multi-organ dysfunction $(13.5 \%)$ followed by CNS $(9.4 \%)$ respiratory $(8.3 \%)$, cardiac $(4.2 \%)$, liver $(4.2 \%)$, then others. In contrast major organ involved in maternal death were respiratory $(24.3 \%)$, CNS $(21.6 \%)$, sepsis leading to multi-organ dysfunction $(21.6 \%)$, hematologic
(10.8\%), then liver $(8.1 \%)$, genital $(8.1 \%)$ and others. Reena RP et al in their study showed the hematological/coagulation system dysfunction was the most common $(71.8 \%)$ followed by respiratory $(15.6 \%)$, hepatic $(12.5 \%)$, and renal dysfunction $(3 \%){ }^{8}$

Of the all women in maternal near miss $34.4 \%$ had vaginal delivery, 29.2 delivered by caesarean section. In maternal death group $40.6 \%$ patient died undelivered, $43.2 \%$ are delivered vaginally, $8.1 \%$ patient required caesarean section. Reena RP et al in their study showed major surgical interventions including cesarean section, obstetric hysterectomy, and laparotomy were required in $75 \%$ of women. ${ }^{8}$

Maximum patients $(56.3 \%)$ had personal problems leading to delayed arrival to hospital, $24 \%$ had logistic problem, $19.8 \%$ person had facility lack in maternal near miss group whereas $51.4 \%$ had personal problems leading to delayed arrival to hospital, $18.9 \%$ had logistic problems $24.3 \%$ had facility related problems, $5.4 \%$ were health personnel related issues in maternal death group. Reena RP et al in their study identified delays in $65.6 \%$ of the near-miss cases. ${ }^{8}$

\section{CONCLUSION}

Hemorrhage, hypertensive disorders and sepsis were the leading causes of near miss events as well as maternal deaths. Rupture uterus also contribute a good portion of maternal near miss and maternal death. Maximum patients there were no/poor antenatal care and coming from rural area that reflects poor quality of services in rural area. That indirectly tells to improve the health education regarding the importance of antenatal care in the rural area so that the incidence can be reduced in both the group maternal near miss and maternal death. Lack of facilities at highest referral centre is the need of the hour to be addressed to reduce MNM and maternal death. Non-availability of dedicated obstetric ICU was noted to be one of the obstacles in treating the critically ill mothers. Limited knowledge experience in critical care management of obstetric patients may be another cause for poor outcome. As it was the $1^{\text {st }}$ study of this kind done in this area, study suggest further and larger study to analyse the loop holes in health care delivery system which will help to improve the quality of maternal care as well as to decrease the maternal mortality ratio in this area. As near miss analysis indicates quality of health care, it is worth presenting in national indices.

\section{ACKNOWLEDGMENTS}

Authors would like to thank faculties and post graduate students for their help.

\author{
Funding: No funding sources \\ Conflict of interest: None declared \\ Ethical approval: The study was approved by the \\ Institutional Ethics Committee
}




\section{REFERENCES}

1. Pattinson R, Say L, Souza JP, van den Broek N, Rooney C. WHO maternal death and near-miss classifications. Bull World Health Organ. 2009;87:734.

2. Costello A, Azad K, Barnett S. An alternative strategy to reduce maternal mortality. Lancet. 2006;368:1477-9.

3. Pattinson RC, Hall M. Near misses: a useful adjunct to maternal death enquiries. $\mathrm{Br}$ Med Bull. 2003;67:231-43.

4. Prual A, Bouvier-Colle MH, de Bernis L, Bréart G. Severe maternal morbidity from direct obstetric causes in West Africa: Incidence and case fatality rates. Bull World Health Org. 2000;78:593-602.

5. Say L, Pattinson RC, Gulmezoglu AM. WHO systematic review of maternal morbidity and mortality: the prevalence of severe acute maternal morbidity (near miss). Reprod Health. 2004;1:3.

6. Sangeeta G, Leena W, Taru G, Sushma K, Nupur G, Amrita $\mathrm{P}$, et al. Evaluation of severe maternal outcomes to assess quality of maternal health care at a tertiary center. J Obstet Gynaecol India. 2015;65:23-7.

7. Ps R, Verma S, Rai L, Kumar P, Pai MV, Shetty J. "Near miss" obstetric events and maternal deaths in a tertiary care hospital: an audit. J Preg. 2013;2013.

8. Reena RP, Radha KR. Factors associated with maternal near miss: A study from Kerala. Indian J Pub Health. 2018;62(1):58.

9. Ghazal-Aswad S, Badrinath P, Sidky I, Safi TH, Gargash H, Abdul-Razak Y, et al. Severe acute maternal morbidity in a high-income developing multi-ethnic country. Mat Child Health J. 2013;17(3):399-404.

10. Donati S, Senatore S, Ronconi A, Regional Maternal Mortality Working G. Obstetric near-miss cases among women admitted to intensive care units in Italy. Acta Obstet Gynecol Scand. 2012;91(4):452-7.

11. Zanconato G, Cavaliere E, Iacovella C, Vassanelli A, Schweiger V, Cipriani S, et al. Severe maternal morbidity in a tertiary care centre of northern Italy: a 5-year review. The J Maternal-Fetal Neonat Med. 2012;25(7):1025-8.

12. Wilson RE, Salihu HM. The paradox of obstetric "near misses": converting maternal mortality into morbidity. Int J Fertil Womens Med. 2007;52(23):121-7.

13. Adeoye IA, Onayade AA, Fatusi AO. Incidence, determinants and perinatal outcomes of near miss maternal morbidity in Ile-Ife Nigeria: a prospective case control study. BMC Preg Childbirth. 2013;13:93.

14. Nelissen EJT, Mduma E, Ersdal HL, Evjen-Olsen B, Roosmalen JJM, Stekelenburg J. Maternal near miss and mortality in a rural referral hospital in northern Tanzania: a cross-sectional study. BMC Preg Childbirth. 2013;13(1):141.

15. van den Akker $\mathrm{T}$, van Rhenen J, Mwagomba B, Lommerse K, Vinkhumbo S, van Roosmalen J. Reduction of severe acute maternal morbidity and maternal mortality in Thyolo District, Malawi: the impact of obstetric audit. PLoS One. 2011;6(6):20776.

16. Gebrehiwot Y, Tewolde BT. Improving maternity care in Ethiopia through facility-based review of maternal deaths and near misses. Int $\mathbf{J}$ Gynecol Obstet. 2014;127:S29-S34.

17. Ali AA, Khojali A, Okud A, Adam GK, Adam I. Maternal near-miss in a rural hospital in Sudan. BMC Preg Childbirth. 2011;11(1):48.

18. Chandran JR, Raj SV, Devi SD. Maternal near miss reviews from a tertiary care center in South India. Int J Reprod Contracept Obstate Gynecol. 2016;5(8):2657-60.

Cite this article as: Sarkar P, Baidya JL, Rakshit AK. A study to assess proportion of the maternal near miss to maternal death in a tertiary care teaching hospital of North East India. Int J Reprod Contracept Obstet Gynecol 2020;9:2486-91. 